\title{
Skin Infections due to Bacteria in Solid Organ Transplant Recipients: A Review
}

\author{
Muneeb llyas Nishita Maganty Zachary Ginsberg Amit Sharma \\ Department of Dermatology, Mayo Clinic Arizona, Scottsdale, AZ, USA
}

\section{Keywords}

Bacterial skin infections - Organ transplantation .

Staphylococcus · Streptococcus . Pseudomonas - Escherichia

coli $\cdot$ Nocardia $\cdot$ Mycobacteria $\cdot$ Bartonella henselae

\begin{abstract}
Though there is an abundance of information on cutaneous malignancies in transplant recipients, cutaneous infections in solid organ transplant recipients (SOTRs) are underrepresented in the dermatological literature. Our paper provides a comprehensive review of bacterial cutaneous infections within the solid organ transplant population. Cutaneous bacterial infections may lead to significant morbidity and even mortality in this immunosuppressed population. Thus, it is to the benefit of both dermatologists and other transplant care providers to better understand and recognize the features of cutaneous bacterial infections in SOTRs. This paper can aid providers in promptly identifying, diagnosing, and treating bacterial skin infections. This review discusses the diagnosis and treatment of the following bacterial species: Staphylococcus, Streptococcus, Pseudomonas aeruginosa, Escherichia coli, Nocardia, Mycobacteria, and Bartonella henselae.

(c) 2018 S. Karger AG, Basel
\end{abstract}

Muneeb Ilyas and Nishita Maganty contributed equally to this work.

\section{KARGER}

() 2018 S. Karger AG, Basel

E-Mail karger@karger.com

www.karger.com/drm

\section{Introduction}

Due to their being on immunosuppressive medications, solid organ transplant recipients (SOTRs) are afflicted with a wide array of cutaneous diseases. Despite the abundant literature on cutaneous malignancies in SOTRs, information on the diagnosis and management of bacterial skin infections is underrepresented. Bacterial infections can present with a variety of symptoms and may cause significant morbidity in SOTRs (Table 1). Therefore, it is beneficial for transplant care providers to recognize the spectrum and management of bacterial cutaneous infections.

\section{Materials and Methods}

For further details, see the online supplementary material (see www.karger.com/doi/10.1159/000484405) (Fig. 1).

\section{Infection Types and Treatment}

\section{Cutaneous Staphylococcal Infection}

Prior to transplantation, Staphylococcus aureus colonizes the anterior nares of $67 \%$ of transplant candidates $[1,2]$ compared to $50 \%$ of immunocompetent individuals 
Table 1. Sources of bacterial skin infections and their cutaneous manifestations in SOTRs

\begin{tabular}{ll}
\hline Bacterial species & Diagnoses \\
\hline Staphylococcus & Folliculitis \\
& Impetigo contagiosa \\
& Bullous impetigo \\
& Ecthyma \\
& Necrotizing fasciitis \\
& Staphylococcal scalded skin \\
& syndrome \\
& MRSA infection \\
\hline Streptococcus & Impetigo contagiosa \\
& Ecthyma \\
\hline Pseudomonas aeruginosa & Cellulitis \\
\hline Escherichia coli & Necrotizing fasciitis \\
\hline Nocardia & Ecthyma gangrenosum \\
\hline Mycobacteria & Necrotizing fasciitis \\
\hline Bartonella & Nocardiosis \\
\hline & Nontuberculous mycobacterial \\
& infection \\
& Miliary tuberculosis \\
& Leprosy \\
\hline & Bacillary angiomatosis \\
\hline
\end{tabular}

[3]. In SOTRs, a majority of nasal carriers of $S$. aureus have methicillin-resistant $S$. aureus (MRSA), which if not properly eradicated can lead to bacteremia after transplantation. Folliculitis is an infection of the superficial hair follicle and the most prevalent cutaneous manifestation of $S$. aureus infection in the first 6 months following transplantation [4]. Hogewoning et al. [5] suggest that high-dose immunosuppression predisposes patients to folliculitis due to a diminished immune response. A study [6] found that folliculitis was significantly more prevalent in a group of Egyptian renal transplant recipients than an immunocompetent control group (10.3 vs. $1.7 \%$, respectively). Euvrard et al. [7] found that $6.2 \%$ of pediatric SOTRs developed folliculitis. Methicillin-sensitive S. aureus (MSSA) folliculitis presents as follicular pustules and papules most commonly on the scalp and face [8]. MRSA folliculitis is more likely to occur on the trunk and scrotum when compared to MSSA [9]. Folliculitis is treated with topical antibiotics such as mupirocin or clindamycin and antibacterial washes [10]. If MSSA folliculitis is widespread, a 7- to 10-day course of oral dicloxacillin $500 \mathrm{mg}$ q.i.d. or oral cephalexin $500 \mathrm{mg}$ q.i.d. may be pursued [8]. If MRSA is cultured, a 7- to 14-day course of oral clinda-

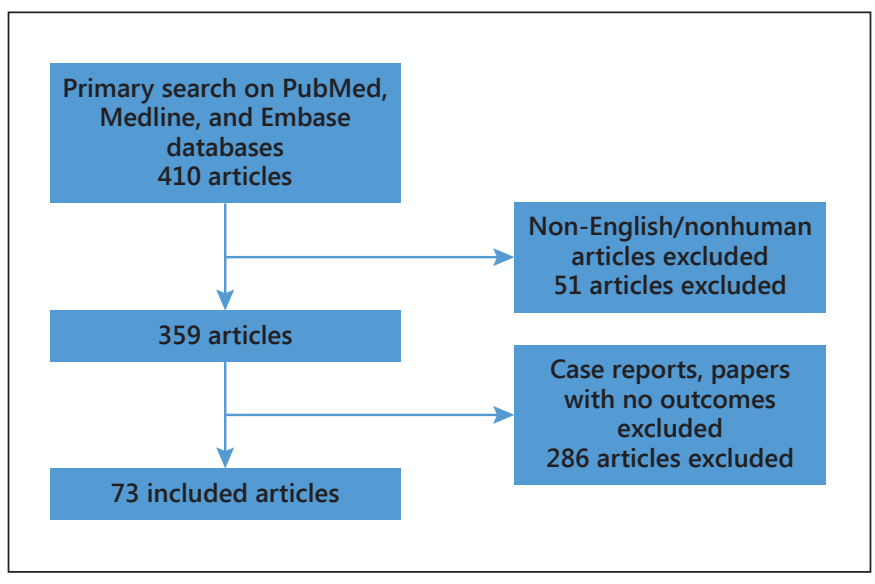

Fig. 1. Flowchart of the literature search.

mycin $450 \mathrm{mg}$ q.i.d. or oral doxycycline $100 \mathrm{mg}$ b.i.d. can be used to resolve symptoms [9].

Impetigo contagiosa, or nonbullous impetigo, is a skin infection associated with species of Staphylococcus or Streptococcus. Patients present with thin-walled vesicles and pustules that later rupture. The residual exudate leaves a classic golden crust [11]. In contrast to impetigo contagiosa, bullous impetigo is associated strictly with staphylococcal infection, particularly strains that produce exfoliative toxin $\mathrm{A}$, which targets the protein desmoglein 1 [12]. Bullous impetigo presents with vesicles that rapidly progress to sharply demarcated, serous or yellow fluid-filled superficial bullae. These bullae easily denude and leave behind a crusted erosion. Hogewoning et al. [5] found that $6.7 \%$ of renal transplant recipients developed impetigo of some form. Topical antibiotics, such as mupirocin ointment applied 3 times a day for 5 days, is the preferred treatment for limited impetigo [13], but widespread disease is best managed with systemic antibiotics [14]. Oral dicloxacillin $500 \mathrm{mg}$ q.i.d. or oral cephalexin $500 \mathrm{mg}$ q.i.d. for 7 days are the recommended treatment options for extensive impetigo [15]. If impetigo is suspected to be caused by MRSA, a 14-day course of oral clindamycin $450 \mathrm{mg}$ q.i.d. or oral doxycycline $100 \mathrm{mg}$ b.i.d. should be used [9].

Ecthyma is an ulcerative cutaneous infection commonly seen on the shins or dorsal feet. It initially presents as a painless macule that becomes painful within $24 \mathrm{~h}$ and develops into a hemorrhagic vesicle. These vesicles then rupture, leaving behind ulceration with a central black necrotic eschar. The most common causes of ecthyma in SOTRs are staphylococcal and streptococcal species. Ecthyma is treated with systemic antibiotics including oral 
dicloxacillin $500 \mathrm{mg}$ q.i.d. or oral cephalexin $500 \mathrm{mg}$ q.i.d. for 7 days [15].

Staphylococcal species can also cause necrotizing fasciitis (NF). NF is a devastating cutaneous infection, especially so in the transplant population. NF spreads through the superficial fascia, subcutaneous fat, and deep fascia. It is most commonly seen in the extremities and abdominal wall [16]. NF is associated with a mortality rate between 25 and $30 \%$ and is diagnosed in 0.04 cases per 1,000 person-years within the general population [17]. Along with immunosuppression, other risk factors for NF include older age, diabetes, atherosclerosis, and drug or alcohol addiction [18]. Although commonly due to polymicrobial infection, staphylococcal species may be implicated [19]. Transplant recipients with NF are also much more likely to present with shock (50\%) when compared to a control group (20.2\%) [17]. Treatment of NF requires emergent surgical debridement along with broad-spectrum antimicrobial therapy with the addition of either intravenous vancomycin at $15-20 \mathrm{mg} / \mathrm{kg} /$ dose every $8_{-}$ $12 \mathrm{~h}$ or intravenous daptomycin $4 \mathrm{mg} / \mathrm{kg}$ once daily to cover for MRSA [20]. In severe cases, amputation may need to be considered to prevent mortality $[18,19]$.

$S$. aureus is capable of releasing epidermolytic toxins (ETA and ETB), which can cause a potentially fatal condition called staphylococcal scalded skin syndrome (SSSS) [21-23]. Clinically, SSSS develops as a scalantiform eruption with flaccid blister formation and a positive Nikolsky sign (Fig. 2a, b). It is seen particularly in the periorificial and flexural areas, although diffuse cutaneous involvement with large regions of epidermal shedding may be seen [24]. Other findings include fever, facial edema, fissures on the lips, and purulent conjunctivitis [25]. SSSS is normally seen in infants or young children and tends to self-resolve in these populations. However, in SOTRs, multisystem failure and electrolyte disturbance associated with SSSS can be potentially fatal [26]. The diagnosis is confirmed with biopsy or with a frozen section of a skin sample [26]. A Gram stain may be negative because the progression of the condition is due to toxin and not the presence of the bacteria itself [25]. Treatment is initiated with a parenteral penicillinase-resistant antistaphylococcal antibiotic such as intravenous flucloxacillin $500 \mathrm{mg}$ per day, divided into 4 portions [27]. If the patient fails to improve following antistaphylococcal antibiotic therapy, MRSA should be considered as a possible source of infection and switching treatment to vancomycin may be considered [28]. Additionally, supportive skin care, intravenous fluids, and admission to the ICU or burn unit may be necessary depending on disease severity.
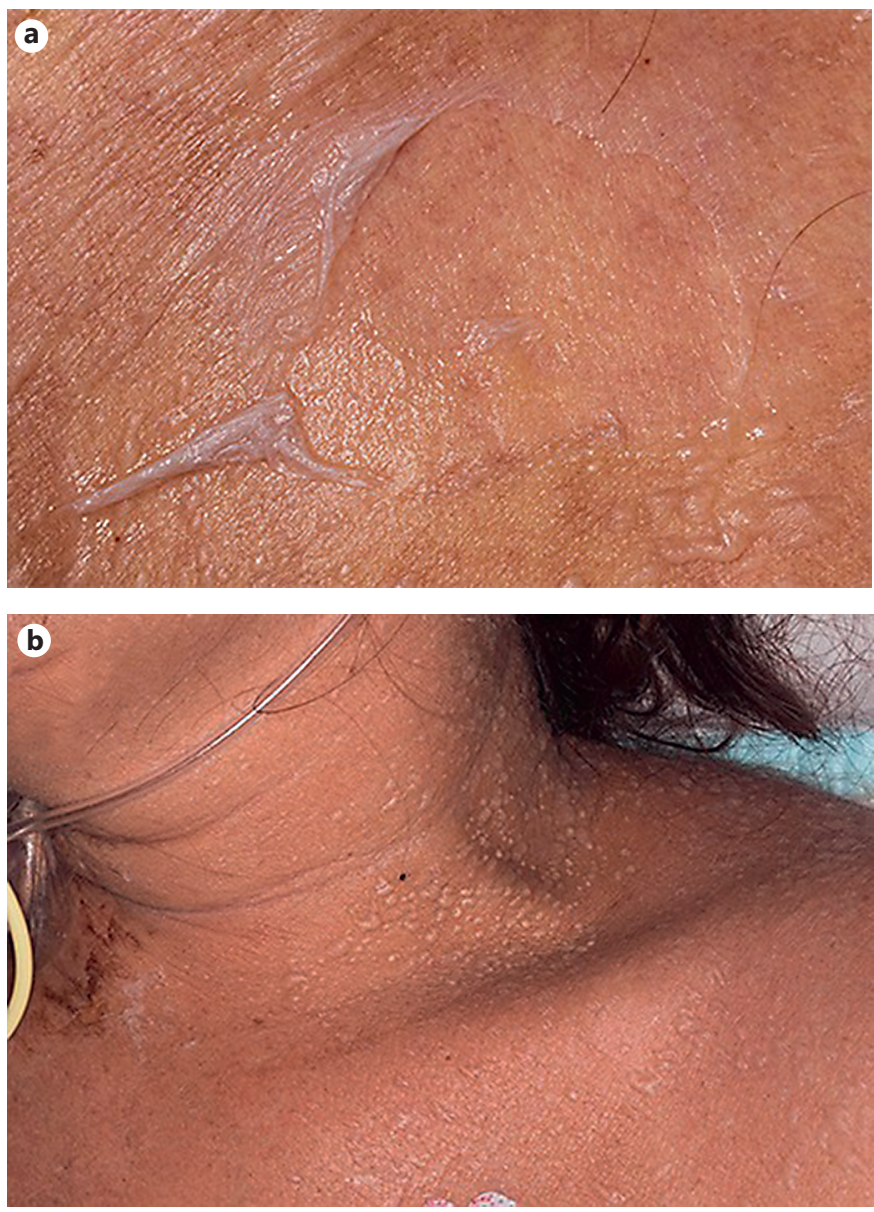

Fig. 2. a, b SSSS presenting with fragile bullae, desquamation, and a positive Nikolsky sign.

In recent years, there has been increasing evidence of community-acquired MRSA skin infections affecting posttransplant patients [29-31]. In 1 study [30], 3 of 11 (27\%) patients with skin or wound infection after lung transplantation were infected with MRSA. Four of 11 (36\%) were infected with MSSA, showing that S. aureus alone was responsible for $63 \%$ of skin or wound infections in lung transplant recipients [30]. Community-acquired MRSA infections are generally susceptible to an array of broad-spectrum antibiotics when compared to hospitalacquired MRSA [30]. A large study [31] on liver transplant recipients found that nasal colonization by $S$. aureus was associated with an increased likelihood of MRSA infection, and patients who developed MRSA infection had twice the risk of death. These findings suggest that SOTRs should be evaluated and treated for nasal MRSA colonization, as this may lower mortality rates in transplant recipients [31,32]. Regardless of MRSA infection 


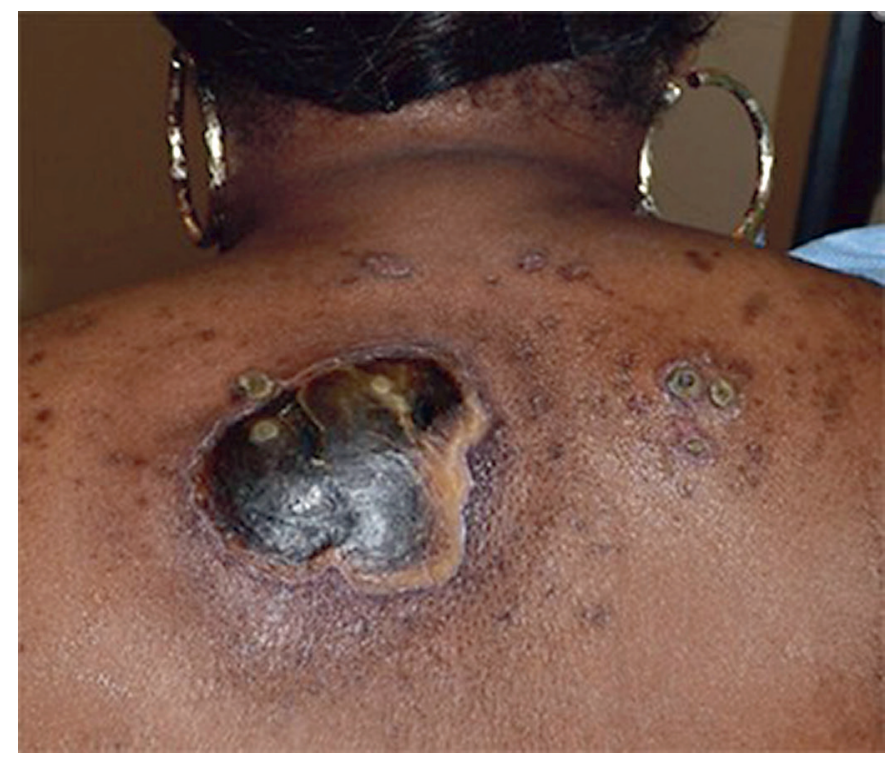

Fig. 3. Ecthyma gangrenosum presenting as a large ulceration with a black necrotic eschar. Reprinted with permission from Frey et al. [74]. Copyright 2014 by the Korean Society of Plastic and Reconstructive Surgeons.

type, sensitivity testing must be conducted owing to potentially large differences in antibiotic resistance between MRSA strains [29].

\section{Cutaneous Streptococcal Infections}

In SOTRs, streptococcal species are associated with causing a variety of skin infections, such as impetigo contagiosa [5], ecthyma, and NF [33]. Streptococcus pyogenes is the most common pathogen to cause monomicrobial NF [17], though Streptococcus pneumoniae has also caused disease in renal transplant recipients [34]. The management of these infections is similar whether infection is due to staphylococcal or streptococcal species.

\section{Cutaneous Pseudomonal Infections}

A severer variant, commonly regarded as a sign of underlying septicemia, is ecthyma gangrenosum (EG). The most common infection associated with EG is Pseudomonas aeruginosa [35]. EG lesions are described as gunmetal gray tense pustules that later evolve into round ulcerations with necrotic black eschars and surrounding erythema (Fig. 3) [35].

Nakai et al. [35] reported a case of EG without associated septicemia in a renal transplant recipient. Even without evidenced bacteremia, the patient showed progression of EG with numerous ulcerations and rapid spread-

Bacterial Skin Infections in Transplant Recipients ing. This case was of particular interest given the presence of both $P$. aeruginosa and MRSA within the wound but the absence of both in the blood. It is imperative to make an early diagnosis and begin treatment promptly for suspected EG in the SOTRs [36]. Even without associated sepsis, immunosuppressed patients can rapidly develop life-threatening disease [35]. EG is treated using antipseudomonal monotherapy with intravenous ticarcillinclavulanate $3.1 \mathrm{~g} / 4 \mathrm{~h}$ (not currently available in the USA or Canada) or intravenous piperacillin-tazobactam $4.5 \mathrm{~g} /$ $6 \mathrm{~h}$ [37]. Although controversial, dual therapy with an antipseudomonal penicillin and an aminoglycoside or other antipseudomonal is recommended in SOTRs [38].

In the renal transplant population, 1 study [39] found that the majority of NF infections (36.4\%) were fungal, likely due to the iatrogenic immunosuppression. P. aeruginosa and Escherichia coli are other infectious causes linked with NF development in the renal transplant population [17]. There has also been a reported case of fatal NF due to carbapenem-resistant Acinetobacter baumannii in a transplant recipient [40].

\section{Cutaneous Escherichia coli Infections}

In SOTRs, 2 cases $[39,41]$ of NF due to E. coli have been described. NF due to $E$. coli is managed with surgical debridement along with dual therapy with ciprofloxacin and imipenem for antimicrobial therapy [39].

\section{Cutaneous Nocardial Infections}

Nocardial infection in the immunocompromised host can lead to localized infection or hematogenous spread, causing disseminated nocardiosis. Localized infection can include ulcers, abscess formation, granulomas, soft tissue infection, and lymphocutaneous infection. In SOTRs, disseminated disease with organ involvement has been described [42]. Disseminated nocardiosis may present with pustules, abscesses, or subcutaneous nodules (Fig. 4) [43]. For diagnosis, both microbiological and histological testing on biopsy specimens should be performed with attempts to culture Nocardia. Depending on infection severity, the immunosuppressive regimen may need to be modified, and combination therapy with imipenem along with either trimethoprim-sulfamethoxazole, amikacin, or linezolid should be started [44]. A study [45] found that SOTRs with nocardiasis treated for a median duration of 56 days had a 1-year cure rate of $88 \%$.

\section{Cutaneous Mycobacterial Infections}

Cutaneous mycobacterial infection in SOTRs is most commonly due to nontuberculous mycobacteria ( $\mathrm{Myco-}$ 


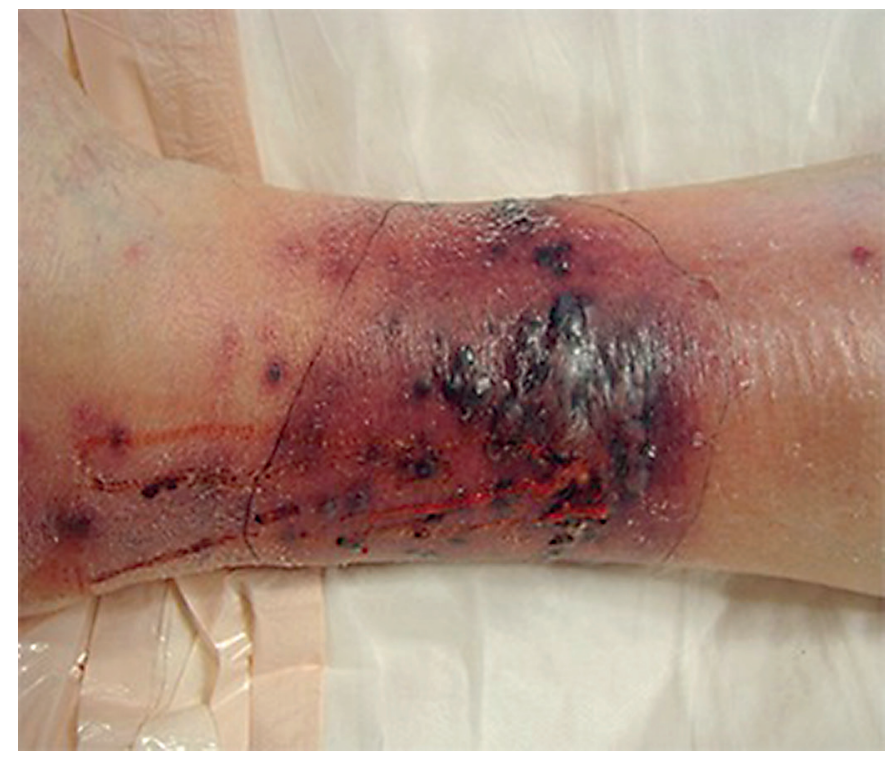

Fig. 4. Disseminated nocardiosis presenting as an indurated, erythematous plaque on the lower extremity. Reprinted with permission from Drone et al. [75]. Copyright 2014 by the Indian Dermatology Online Journal.

bacterium marinum, $M$. haemophilum, $M$. fortuitum, $M$. chelonae, M. abscessus and M. ulcerans, or M. immunogenum), although 2 cases of hematogenous dissemination of $M$. tuberculosis leading to cutaneous tuberculosis have been described [46].

Cutaneous manifestations of mycobacterial infections range from macular erythema to nonhealing ulcers, although erythematous nodules and papules are the most common presentations [46]. In kidney transplant recipients, cutaneous nontuberculous mycobacteria may present with painless, violaceous nodules that can ulcerate and manifest with a sporotrichoid appearance [45].

Hematogenous spread of mycobacterial infection could present as nodules or abscesses. Disseminated disease in transplant recipients is most commonly caused by M. chelonae, presenting with multiple red subcutaneous nodules or abscesses [47]. Additional nontuberculous mycobacteria associated with disseminated infection include M. kansasii, M. haemophilum, M. fortuitum, and others [48]. Other presentations include lupus vulgaris, which presents with small, sharply defined red papules with gelatinous consistency, or acute miliary tuberculosis, which presents with millet-sized red papules that may progress into ulcers and abscesses. Presentations with subcutaneous abscesses, cellulitis, erysipelas, or pseudotumors have also been described $[46,49,50]$.

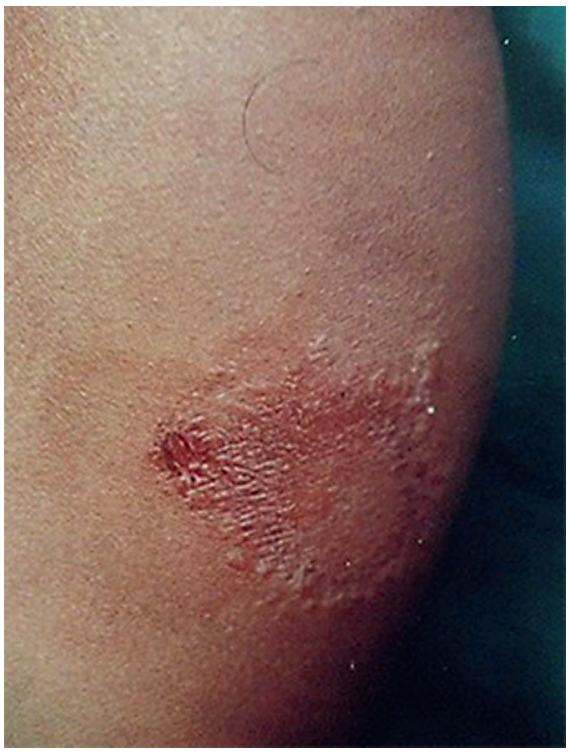

Fig. 5. Tuberculoid leprosy presenting as an annular, anesthetic plaque on the forearm. Reprinted with permission from Thakkar and Patel [76].

There are cases of $M$. leprae causing lepromatous leprosy in SOTRs [51-53]. Infection with $M$. leprae in the SOTR population presents with a variety of cutaneous manifestations (Fig. 5). Currently, there are 16 reported cases of lepromatous leprosy in SOTRs. One case [52] in a heart transplant recipient described the presence of a migratory papular red rash over the upper torso along with violaceous papules on the hands. A report on a renal transplant recipient describes development of a hypoesthetic, hypopigmented patch with thickening and tenderness of an adjacent nerve [51]. Another case describes a renal transplant recipient with erythematous papules and nodules over the face and earlobes, scars on the knee, and purulent discharge and impetiginous crust over the hands and feet [54]. Leprosy infections can range from milder tuberculoid to severe lepromatous infections. Immunosuppression in SOTRs is thought to contribute to disease severity as it reduces T-cell function [53]. All reported cases of lepromatous leprosy in SOTRs occurred in endemic areas or in patients originally from endemic regions [51-53, 55-57]. Currently, there are limited data on the effect of leprosy infection on allograft function or on the association between immunosuppression and leprosy infection.

When mycobacterial infection is being considered, a tissue specimen should be cultured for species identifica- 
tion and sensitivity. Polymerase chain reaction (PCR) may be used for mycobacterial identification owing to the 12 -week period needed to culture mycobacterial species. In the past, PCR only allowed for the differentiation between nontuberculous and tuberculous mycobacteria; However, recent advancements in PCR techniques allow clinicians to distinguish between nontuberculous mycobacterial species [58-61].

Treatment of cutaneous mycobacterial infection depends on the species and sensitivity data. Limited $M$. marinum may be managed with monotherapy using either clarithromycin, doxycycline, minocycline, or trimethoprim-sulfamethoxazole for 3 months. Severe M. marinum skin infection is managed using combination therapy with rifampin and ethambutol [47]. M. ulcerans is managed with rifampin and streptomycin treatment for 8 weeks along with surgical intervention [47]. Guidelines for treating nontuberculous mycobacteria are not clearly defined; hence, infectious disease consultation is advised in transplant recipients who develop mycobacterial infection. For primary prevention, transplant recipients should avoid fish tank water and fresh fish because exposure to these agents is a risk factor for infection with $M$. marinum and other nontuberculous mycobacterial species [49]. Acupuncture is associated with nontuberculous mycobacterial infections, and SOTRs should be appropriately cautioned $[46,62,63]$.

\section{Cutaneous Bartonella henselae Infections}

Bacillary angiomatosis (BA) is a vasculoproliferative disorder caused by Bartonella species [64]. The most common bacterium associated with BA in SOTRs is B. henselae [64]. The classic presentation is with smooth, domed red or violaceous lesions that resemble hemangiomas. Lesions can be solitary or widespread and scattered, normally on the face and extremities. Development of cellulitis or of a large flesh-colored indurated mass is also a possible presentation. These lesions are very vascular and bleed with minor trauma. Additional findings include fever, lymphadenopathy, and vascular nodules within organs [64]. Exposure to the bacterium is most commonly through cats. About $25 \%$ of cases of BA in SOTRs were in the pediatric or adolescent population, despite only $3-4 \%$ of transplant recipients being in this age range [65-69]. BA can be associated with some devastating consequences. There have been documented occurrences of hemophagocytic syndrome and renal graft rejection, both due to $\mathrm{BA}$ in renal transplant recipients $[65,70]$.

BA may have an exceedingly similar presentation to that of Kaposi's sarcoma or pyogenic granuloma. A con- sequence of this similarity is the potential delay in diagnosis and subsequent treatment. A diagnosis can be made with electron microscopy showing clumped and solitary rods within the intercellular space. An alternative is using the Warthin-Starry stain, but this test may be difficult to interpret [64]. Bartonella species are difficult to identify in culture, and a negative result should not rule out disease [71]. Antibiotic therapy with doxycycline $100 \mathrm{mg}$ b.i.d. for 3 months is recommended for BA in HIV patients [71]. Both ciprofloxacin and doxycycline have been used to resolve BA in SOTRs [72, 73].

\section{Conclusion}

SOTRs may present with a wide variety of cutaneous findings. Sources of skin pathology in SOTRs include infection, drug toxicity, and malignancy. Bacterial skin infections can vary in presentation, severity, and prognosis. In order to best reduce disease-associated morbidity and mortality, SOTR care providers must promptly identify, diagnose, and treat bacterial skin infections.

\section{Key Message}

A comprehensive review of bacterial cutaneous infections in the solid organ transplant population is presented.

\section{Disclosure Statement}

The authors have no conflicts of interest to disclose.

References

1 Chang FY, Singh N, Gayowski T, Drenning SD, Wagener MM, Marino IR: Staphylococcus aureus nasal colonization and association with infections in liver transplant recipients. Transplantation 1998;65:1169-1172.

2 Bert F, Bellier C, Lassel L, Lefranc V, Durand F, Belghiti J, Mentre F, Fantin B: Risk factors for Staphylococcus aureus infection in liver transplant recipients. Liver Transpl 2005;11: 1093-1099.

3 Frank DN, Feazel LM, Bessesen MT, Price CS, Janoff EN, Pace NR: The human nasal microbiota and Staphylococcus aureus carriage. PLoS One 2010;5:e10598.

4 Ponticelli C, Bencini PL: Nonneoplastic mucocutaneous lesions in organ transplant recipients. Transpl Int 2011;24:1041-1050.

5 Hogewoning AA, Goettsch W, van Loveren H, de Fijter JW, Vermeer BJ, Bouwes Bavinck JN: Skin infections in renal transplant recipients. Clin Transplant 2001;15:32. 
6 Bakr NI, El-Sawy E, Hamdy AF, Bakr MA: Skin infections in Egyptian renal transplant recipients. Transplant Infect Dis 2011;13: 131-135.

7 Euvrard S, Kanitakis J, Cochat P, Cambazard F, Claudy A: Skin diseases in children with organ transplants. J Am Acad Dermatol 2001; 44:932-939.

8 Laureano AC, Schwartz RA, Cohen PJ: Facial bacterial infections: folliculitis. Clin Dermatol 2014;32:711-714.

9 Cohen PR: Community-acquired methicillinresistant Staphylococcus aureus skin infections: a review of epidemiology, clinical features, management, and prevention. Int $\mathrm{J}$ Dermatol 2007;46:1-11.

10 Lopez FA, Lartchenko S: Skin and soft tissue infections. Infect Dis Clin North Am 2006;20: 759-772, v-vi.

11 Hartman-Adams H, Banvard C, Juckett G: Impetigo: diagnosis and treatment. Am Fam Phys 2014;90:229-235.

12 Amagai M, Matsuyoshi N, Wang ZH, Andl C, Stanley JR: Toxin in bullous impetigo and staphylococcal scalded-skin syndrome targets desmoglein 1. Nat Med 2000;6:1275-1277.

13 Koning S, van der Sande R, Verhagen AP, van Suijlekom-Smit LW, Morris AD, Butler CC, Berger M, van der Wouden JC: Interventions for impetigo. Cochrane Database Syst Rev 2012;1:CD003261.

14 George A, Rubin G: A systematic review and meta-analysis of treatments for impetigo. Br J Gen Pract 2003;53:480-487.

15 Stevens DL, Bisno AL, Chambers HF, Dellinger EP, Goldstein EJ, Gorbach SL, Hirschmann JV, Kaplan SL, Montoya JG, Wade JC; Infectious Diseases Society of America: Practice guidelines for the diagnosis and management of skin and soft tissue infections: 2014 update by the Infectious Diseases Society of America. Clin Infect Dis 2014; 59:e10-e52.

16 Green RJ, Dafoe DC, Raffin TA: Necrotizing fasciitis. Chest 1996;110:219-229.

17 Sarani B, Strong M, Pascual J, Schwab CW: Necrotizing fasciitis: current concepts and review of the literature. J Am Coll Surg 2009; 208:279-288.

18 McHenry CR, Piotrowski JJ, Petrinic D, Malangoni MA: Determinants of mortality for necrotizing soft-tissue infections. Ann Surg 1995;221:558-563; discussion 563-555.

19 Seal DV: Necrotizing fasciitis. Curr Opin Infect Dis 2001;14:127-132.

20 Liu C, Bayer A, Cosgrove SE, Daum RS, Fridkin SK, Gorwitz RJ, Kaplan SL, Karchmer AW, Levine DP, Murray BE, Rybak MJ, Talan DA, Chambers HF: Clinical practice guidelines by the Infectious Diseases Society of America for the treatment of methicillin-resistant Staphylococcus aureus infections in adults and children: executive summary. Clin Infect Dis 2011;52:285-292.
21 Schwartz RA, McDonough PH, Lee BW: Toxic epidermal necrolysis. II. Prognosis, sequelae, diagnosis, differential diagnosis, prevention, and treatment. J Am Acad Dermatol 2013;69:187.e1-187.e16; quiz 203-204.

22 Li MY, Hua Y, Wei GH, Qiu L: Staphylococcal scalded skin syndrome in neonates: an 8-year retrospective study in a single institution. Pediatr Dermatol 2014;31:43-47.

23 Murray RJ: Recognition and management of Staphylococcus aureus toxin-mediated disease. Intern Med J 2005;35(suppl 2):S106S119.

24 Patel GK, Finlay AY: Staphylococcal scalded skin syndrome: diagnosis and management. Am J Clin Dermatol 2003;4:165-175.

25 Sundram U: A review of important skin disorders occurring in the posttransplantation patient. Adv Anat Pathol 2014;21:321-329.

26 Strauss G, Mogensen AM, Rasmussen A, Kirkegaard P: Staphylococcal scalded skin syndrome in a liver transplant patient. Liver Transplant Surg 1997;3:435-438.

27 Greenwood JE, Dunn KW, Davenport PJ: Experience with severe extensive blistering skin disease in a paediatric burns unit. Burns 2000; 26:82-87.

28 Ladhani S, Joannou CL: Difficulties in diagnosis and management of the staphylococcal scalded skin syndrome. Pediatr Infect Dis J 2000;19:819-821.

29 Adeyemi OA, Qi C, Zembower TR, Ison MG, Grant TH, Hartigan BJ, Malczynski M, Stosor $\mathrm{V}$ : Invasive infections with community-associated methicillin-resistant Staphylococcus aureus after kidney transplantation. J Clin Microbiol 2008;46:2809-2813.

30 Gupta MR, Valentine VG, Walker JJE, Lombard GA, LaPlace SG, Seoane L, Taylor DE, Dhillon GS: Clinical spectrum of gram-positive infections in lung transplantation. Transplant Infect Dis 2009;11:424-431.

31 Russell DL, Flood A, Zaroda TE, Acosta C, Riley MMS, Busuttil RW, Pegues DA: Outcomes of colonization with MRSA and VRE among liver transplant candidates and recipients. Am J Transplant 2008;8:1737-1743.

32 Singh N, Paterson DL, Chang FY, Gayowski T, Squier C, Wagener MM, Marino IR: Methicillin-resistant Staphylococcus aureus: the other emerging resistant gram-positive coccus among liver transplant recipients. Clin Infect Dis 2000;30:322-327.

33 Garcia-Casares E, Mateo Soria L, GarciaMelchor E, Riera Alonso E, Olive Marques A, Holgado Perez S, Tena Marsa X, Molinos Abos S: Necrotizing fasciitis and myositis caused by streptococcal flesh-eating bacteria. J Clin Rheumatol 2010;16:382-384.

34 Imhof A, Maggiorini M, Zbinden R, Walter RB: Fatal necrotizing fasciitis due to Streptococcus pneumoniae after renal transplantation. Nephrol Dial Transplant 2003;18:195197.
35 Nakai N, Takenaka H, Kishimoto S: Ecthyma gangrenosum without pseudomonas septicemia in a kidney transplant recipient. J Dermatol 2008;35:585-589.

36 Santos B, Sanz M, Nunez A, Mayor LO, Quiroga B: Ecthyma gangrenosum in a renal transplant recipient. Nefrologia 2016;36:573574.

37 Kanj SS, Kanafani ZA: Current concepts in antimicrobial therapy against resistant gramnegative organisms: extended-spectrum betalactamase-producing Enterobacteriaceae, carbapenem-resistant Enterobacteriaceae, and multidrug-resistant Pseudomonas aeruginosa. Mayo Clin Proc 2011;86:250-259.

38 Bowers DR, Liew YX, Lye DC, Kwa AL, Hsu LY, Tam VH: Outcomes of appropriate empiric combination versus monotherapy for Pseudomonas aeruginosa bacteremia. Antimicrob Agents Chemother 2013;57:12701274.

39 Tsai SF: Necrotizing fasciitis in patients who underwent renal transplantation. Transplant Proc 2013;45:2807-2810.

40 Clemente WT, Sanches MD, Coutinho RL, de Oliveira Junior AR, Lauria MW, Lima CX, de Castro Romanelli RM: Multidrug-resistant Acinetobacter baumannii causing necrotizing fasciitis in a pancreas-kidney transplant recipient: a case report. Transplantation 2012; 94:e37-e38.

41 Turunc V, Eroglu A, Cihandide E, Tabandeh B, Orug T, Guven B: Escherichia coli-related necrotizing fasciitis after renal transplantation: a case report. Transplant Proc 2015;47: 1518-1521.

42 Chapman SW, Wilson JP: Nocardiosis in transplant recipients. Semin Respir Infect 1990;5:74-79.

43 Caroti L, Zanazzi M, Rogasi P, Fantoni E, Farsetti S, Rosso G, Bertoni E, Salvadori M: Subcutaneous nodules and infectious complications in renal allograft recipients. Transplant Proc 2010;42:1146-1147.

44 De La Cruz O, Minces LR, Silveira FP: Experience with linezolid for the treatment of nocardiosis in organ transplant recipients. J Infect 2015;70:44-51.

45 Lebeaux D, Freund R, van Delden C, Guillot $\mathrm{H}$, Marbus SD, Matignon M, Van Wijngaerden E, Douvry B, De Greef J, Vuotto F, Tricot L, Fernandez-Ruiz M, Dantal J, Hirzel C, Jais JP, Rodriguez-Nava V, Jacobs F, Lortholary O, Coussement J; European Study Group for Nocardia in Solid Organ Transplantation: Outcome and treatment of nocardiosis after solid organ transplantation: new insights from a European study. Clin Infect Dis 2017;64:1396-1405.

46 Seyahi N, Apaydin S, Kahveci A, Mert A, Sariyar M, Erek E: Cellulitis as a manifestation of miliary tuberculosis in a renal transplant recipient. Transplant Infect Dis 2005;7:80-85.

47 Gonzalez-Santiago TM, Drage LA: Nontuberculous mycobacteria: skin and soft tissue infections. Dermatol Clin 2015;33:563-577. 
48 Ferreira RM, Saad MH, Silva MG, Fonseca L de S: Non-tuberculous mycobacteria. I. One year clinical isolates identification in Tertiary Hospital Aids Reference Center, Rio de Janeiro, Brazil, in pre highly active antiretroviral therapy era. Mem Inst Oswaldo Cruz 2002;97: 725-729.

49 Lovric S, Becker JU, Kayser D, Wagner A, Haubitz M, Kielstein JT: Fish, flesh and a good red herring: a case of ascending upper limb infection in a renal transplant patient. Clin Nephrol 2009;72:402-404.

50 Rahmani M, Alroy J, Zoukhri D, Wein RO, Tischler AS: Mycobacterial pseudotumor of the skin. Virchows Arch 2013;463:843-846.

51 Agarwal DK, Mehta AR, Sharma AP, Sural S, Kumar A, Mehta B, Gupta A, Sharma RK, Gupta RK: Coinfection with leprosy and tuberculosis in a renal transplant recipient. Nephrol Dial Transplant 2000;15:1720-1721.

52 Modi K, Mancini M, Joyce MP: Lepromatous leprosy in a heart transplant recipient. Am J Transplant 2003;3:1600-1603.

53 Ardalan M, Ghaffari A, Ghabili K, Shoja MM: Lepromatous leprosy in a kidney transplant recipient: a case report. Exp Clin Transplant 2011;9:203-206.

54 Aytekin S, Yasar S, Goktay F, Cebeci F, Duran A, Gunes P, Sahin GM: Lepromatous leprosy in a renal transplant recipient. Am J Transplant 2017;17:2224-2226.

55 Shih HC, Hung TW, Lian JD, Tsao SM, Hsieh NK, Yang JH: Leprosy in a renal transplant recipient: a case report and literature review. J Dermatol 2005;32:661-666.

56 Mushatt DM, Wattanamano P, Alvarado FS: Lepromatous leprosy in a renal transplant recipient. Clin Infect Dis 1998;26:217-218.

57 Guditi S, Ram R, Ismal KM, Sahay M, Dakshinamurthy KV, Girish N, Prasad N: Leprosy in a renal transplant recipient: review of the literature. Transpl Infect Dis 2009;11:557-562.

58 Kraus G, Cleary T, Miller N, Seivright R, Young AK, Spruill G, Hnatyszyn HJ: Rapid and specific detection of the Mycobacterium tuberculosis complex using fluorogenic probes and real-time PCR. Mol Cell Probes 2001;15:375-383.

59 Lachnik J, Ackermann B, Bohrssen A, Maass S, Diephaus C, Puncken A, Stermann M, Bange FC: Rapid-cycle PCR and fluorimetry for detection of mycobacteria. J Clin Microbiol 2002;40:3364-3373.

60 Springer B, Stockman L, Teschner K, Roberts GD, Bottger EC: Two-laboratory collaborative study on identification of mycobacteria: molecular versus phenotypic methods. J Clin Microbiol 1996;34:296-303.

61 Shrestha NK, Tuohy MJ, Hall GS, Reischl U, Gordon SM, Procop GW: Detection and differentiation of Mycobacterium tuberculosis and nontuberculous mycobacterial isolates by real-time PCR. J Clin Microbiol 2003;41: 5121-5126.

62 Woo PC, Li JH, Tang W, Yuen K: Acupuncture mycobacteriosis. N Engl J Med 2001;345: 842-843.

63 Tang P, Walsh S, Murray C, Alterman C, Varia M, Broukhanski G, Chedore P, DeKoven J, Assaad D, Gold WL, Ghazarian D, Finkelstein M, Pritchard M, Yaffe B, Jamieson F, Henry B, Phillips E: Outbreak of acupuncture-associated cutaneous Mycobacterium abscessus infections. J Cutan Med Surg 2006;10:166169.

64 Moulin C, Kanitakis J, Ranchin B, Chauvet C, Gillet Y, Morelon E, Euvrard S: Cutaneous bacillary angiomatosis in renal transplant recipients: report of three new cases and literature review. Transpl Infect Dis 2012;14:403409.

65 Apalsch AM, Nour B, Jaffe R: Systemic catscratch disease in a pediatric liver transplant recipient and review of the literature. Pediatr Infect Dis J 1993;12:769-774.

66 Dharnidharka VR, Richard GA, Neiberger RE, Fennell RS 3rd: Cat scratch disease and acute rejection after pediatric renal transplantation. Pediatr Transplant 2002;6:327-331.

67 Rheault MN, van Burik JA, Mauer M, Ingulli E, Ferrieri P, Jessurun J, Chavers BM: Catscratch disease relapse in a kidney transplant recipient. Pediatr Transplant 2007;11:105109.

68 Juskevicius R, Vnencak-Jones C: Pathologic quiz case: a 17 -year-old renal transplant patient with persistent fever, pancytopenia, and axillary lymphadenopathy. Bacillary angiomatosis of the lymph node in the renal transplant recipient. Arch Pathol Lab Med 2004; 128:e12-e14.

69 Scolfaro C, Mignone F, Gennari F, Alfarano A, Veltri A, Romagnoli R, Salizzoni M: Possible donor-recipient bartonellosis transmission in a pediatric liver transplant. Transpl Infect Dis 2008;10:431-433.

70 Karras A, Thervet E, Legendre C; Groupe Cooperatif de transplantation d'Ile de France: Hemophagocytic syndrome in renal transplant recipients: report of 17 cases and review of literature. Transplantation 2004;77:238243

71 Rolain JM, Brouqui P, Koehler JE, Maguina C, Dolan MJ, Raoult D: Recommendations for treatment of human infections caused by Bartonella species. Antimicrob Agents Chemother 2004;48:1921-1933.

72 Patel SJ, Petrarca R, Shah SM, Zimmer-Galler I, Janjua KA, Do DV, Nguyen QD: Atypical Bartonella henselae chorioretinitis in an immunocompromised patient. Ocul Immunol Inflamm 2008;16:45-49.

73 Nadimi AE, Cheng K, Radfar A: Bacillary angiomatosis from Bartonella quintana in a cardiac transplant patient. J Am Acad Dermatol 2016;74:AB150.

74 Frey JD, Latkowski J-AM, Louie E, Chiu ES: Diagnosis and management of ecthyma gangrenosum in chronic renal failure patient. Arch Plastic Surg 2014;41:299.

75 Drone ER, McCrory AL, Lane N, Fiala K: Disseminated nocardiosis in a patient on infliximab and methylprednisolone for treatmentresistant Sweet's syndrome. Indian Dermatol Online J 2014;5:300.

76 Thakkar S, Patel SV: Clinical profile of leprosy patients: a prospective study. Indian $\mathrm{J}$ Dermatol 2014;59:160
Bacterial Skin Infections in Transplant Recipients
Dermatology 2017;233:358-365

DOI: $10.1159 / 000484405$ 